\title{
The Determination of Total Alkaloid, Polyphenol, Flavonoid and Saponin Contents of Pogang gan (Curcuma sp.)
}

\author{
Phan Van $\operatorname{Tan}^{1}$ \\ ${ }^{1}$ Faculty of Agriculture and Forestry. Taynguyen University, Buonmathuot city, Vietnam \\ Correspondence: Phan Van Tan, Faculty of Agriculture and Forestry. Taynguyen University, Buonmathuot city, \\ Vietnam. E-mail: phvtan56@yahoo.com
}

Received: April 4, 2018

doi:10.5539/ijb.v10n4p42
Accepted: April 25, $2018 \quad$ Online Published: September 25, 2018

URL: https://doi.org/10.5539/ijb.v10n4p42

\begin{abstract}
Pogang gan (Curcuma sp., Zingiberaceae family) is medicinal herb and threatened and it is usually used as a tonic. We successfully micropropagated and cultivated this species. This study determined the total alkaloid, polyphenol, flavonoid and saponin contents of its growth time in order to determine harvest time. The highest level of total alkaloid content is roots after 11 months cultivation $(0.272 \mathrm{mg} / \mathrm{g})$, total polyphenol content is rhizomes after 11 months ( $1.71 \mathrm{mg} \mathrm{GAE} / \mathrm{g})$, total flavonoid content is rhizomes after 11 months $(13.89 \mathrm{mg} \mathrm{QE} / \mathrm{g})$ and total saponin content is tubers and roots after 11 months $(5.26 \%$ and $4.78 \%)$. The total content of alkaloid and flavonoid of pogang gan is higher than Curcuma zedoaria. The total saponin content of natural pogang gan is equal to $39.5 \%$ of 6-year old Vietnamese ginseng and the saponin content in rhizomes and tubers of 11-month-planted Pogang gan is from 55.5\% to 67.8\%, compared with natural Pogang gan.
\end{abstract}

Keywords: pogang gan, Curcuma sp., alkaloid, polyphenol, flavonoid, saponin

\section{Introduction}

The medicinal herb Pogang gan (Curcuma sp., Zingiberaceae family) has the narrow habit and low reserve, but it is usually used as a tonic. According to Bana ethnic, Pogang gan is as considered a medicine for the human. We successfully have propagated this species (Van Tan, 2016) but we have not determined the science name of Pogang gan's species yet because its inflorescence has been found. There are a lot of points in genus Curcuma among Curcuma vitellina, C. singularis and pogang gan via DNA analysis (Van Tan \& Vinh, 2015).

Alkaloid, polyphenol, flavonoid and saponin have high pharmaceutical value and are rich of antioxidant, which are able to against free radicals and reduce blood fat (Drug Enforcement Administration (DEA), 2010). There for scientists are screening medicinal herbs which contain the mentioned matter to use them as medicine. Pogang gan (Curcuma sp.) contains higher contents of polyphenol, alkaloid, saponin than other species in the Curcuma genus, (good at heart operation and circulatory system and improves the people's health (Van Tan \& Vinh, 2015)). However, we need to specify the content of the mentioned matter in rhizome, tuber and small root during the growing time in order to determine harvest time. Among the species of the Curcuma genus, white turmeric (Curcuma zedoaria Rosc.) is planted popularly in Vietnam and has a great value and contains high content of alkaloid, polyphenol and flavonoid (Dutta, 2015).

Vietnamese ginseng (Panax vietnamensis Ha \& Grushv.) is the medicine which has a very high value, high saponin content and many other matters of saponin (Duc et al., 1993; Nguyen et al., 1995) that has higher value than other ginsengs (Report of Ministry of Health of Vietnam, 1978).

Total alkaloid, polyphenol, flavonoid and saponin contents are determined by contents in the underground parts of pogang gan and the proper harvest time of Pogang gan in order to evaluate the value of natural pogang gan and planted pogang gan, combined with white turmeric and vietnamese ginseng. This is the foundation to preserve and develop pogang gan.

\section{Materials and Research Method}

\subsection{Materials Used in the Research}

With regards to pogang gan, we used the parts: rhizomes, tubers and small roots which are collected from 2 places: Kon Bong 2 village, Dak Rong commune, Kbang distric, Gia Lai province (nature) and Chu Yang Shin 
National garden, Krong Bong distric, DakLak Province (planted). The plants were harvested after 6 months and 11 months of the growth. Pogang gan was cultivated after 10 months the leaves and stems have faded only underground (rhizomes, tubers and roots) is alive (dormancy).

For white turmeric (Curcuma zedoaria Rosc.), we used rhizomes and tubers parts which was cultivated in DakLak province after 11 months.

For vietnamese ginseng (Panax vietnamensis Ha \& Grushv.), rhizomes of plants which were cultivated in Dak Glei district, Kon Tum province after 6 years are used for this research.

All samples were dried up by solar energy, to reach the humidity $12 \%$

\subsection{Research Method}

Sample-signs:

Ta0: rhizomes and tubers of white turmeric (Curcuma zedoaria Rosc.);

TaN: rhizomes and tubers of natural pogang gan (Curcuma sp.), after buds sprouting 11 months;

Ta1: rhizomes and tubers of pogang gan after 11-month-cultivated; at that time the aerial stems and leaves faded but root system is alive

Ta2: rhizomes of cultivated pogang gan after 6 months cultivated; at that time the trees have formated rhizomes and tubers;

Ta3: tubers of pogang gan after 11 months cultivated;

Ta4: tubers pogang gan after 6 months cultivated;

Ta5: small roots of pogang gan after 11 months cultivated;

SNL: rhizomes of 6 years old vietnamese gingseng (Panax vietnamensis);

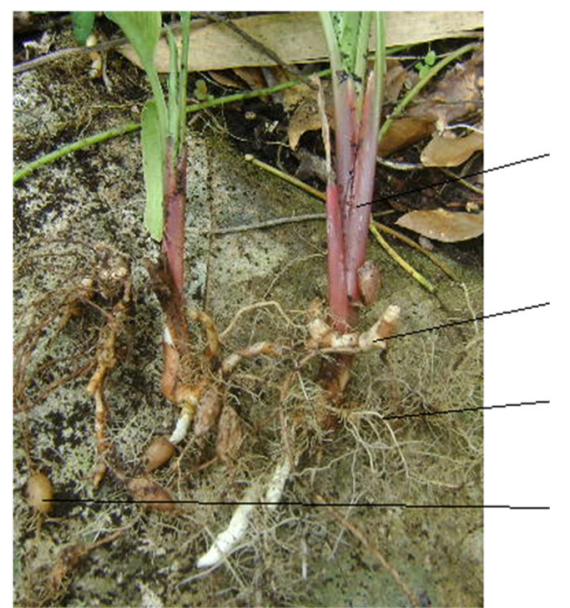

(a)

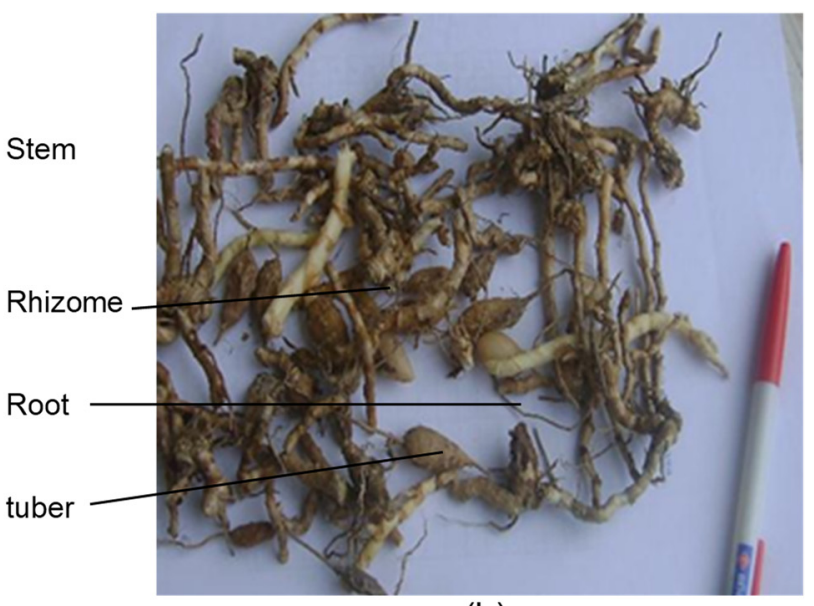

(b)

Figure 1. pogang gan: (a) trees of pogang gan; (b) a parts used (freshing)

In order to evaluate the contents of alkaloid, polyphenol, flavonoid and saponin, after drying up by solar energy, samples were desiccated at $105^{\circ} \mathrm{C}$ in 4 hours. All test analysis were repeated 5 times.

\subsubsection{Determine Total Alkaloid Content}

Determine total alkaloids by method of Shamsa, Monsef, Ghamooshi, and Verdian-rizi (2008).

\section{Solution Preparation}

Bromocresol green (BCG) solution were prepared by heating $69.8 \mathrm{mg}$ bromocresol green with $3 \mathrm{ml} \mathrm{NaOH} 2 \mathrm{~N}$ and $5 \mathrm{ml}$ distilled water until completely dissolved. The solution was diluted to $1000 \mathrm{ml}$ with distilled water. Phosphate buffer solution ( $\mathrm{pH}$ 4.7) was prepared by adjusting the $\mathrm{pH}$ of sodium phosphate $2 \mathrm{M}\left(71.6 \mathrm{~g} \mathrm{Na}_{2} \mathrm{HPO}_{4}\right.$ in $1000 \mathrm{ml}$ distilled water) to 4.7 with citric acid (42.02 g citric acid in $1000 \mathrm{ml})$. Atropine standard solution was made by dissolving $1 \mathrm{mg}$ pure atropine (Sigma Chemical, USA) in $10 \mathrm{ml}$ distilled water. 


\section{Preparation of Standard Curve}

Accurately measure aliquots $(0.4,0.6,0.8 .1 .0$ and $1.2 \mathrm{ml})$ of atropine standard solution and transfer each to different separated funnels. Then, add $5 \mathrm{ml} \mathrm{pH}$ phosphate buffer solution and $5 \mathrm{ml} \mathrm{BCG}$ solution and shake the mixture with 1, 2, 3 and $4 \mathrm{ml}$ of chloroform. The extracts were collected in a $10 \mathrm{ml}$ volumetric flask and then diluted to adjust the volume with chloroform. The absorbance of the complex in chloroform was measured at $470 \mathrm{~nm}$ blank prepared as above but without atropine.

\section{Extraction}

The plant materials $(5 \mathrm{~g})$ were ground and extracted with methanol for $24 \mathrm{~h}$ in a continuous extraction apparatus at $26^{\circ} \mathrm{C}$. The extract was filtered and methanol was a rotary evaporator under vacuum at temperature of $45^{\circ} \mathrm{C}$ to dry. A part of this residue was dissolved in $\mathrm{HCl} 2 \mathrm{~N}$ and then filtered. Once $\mathrm{ml}$ this solution was transferred to a separate funnel and washed with $10 \mathrm{ml}$ chloroform (3 times). The $\mathrm{pH}$ of this solution was adjusted to be neutral with $\mathrm{NaOH} 0.1 \mathrm{~N}$. Then $5 \mathrm{ml}$ of BCG solution and $5 \mathrm{ml}$ phosphate buffer were added to this solution. The mixture was shaken and the complex formed was extracted with 1,2,3,4 ml chloroform by vigorous shaking. The extracts were collected in a $10 \mathrm{ml}$ volumetric flask and diluted to volume with chloroform. The absorbance of the complex in chloroform was measured at $470 \mathrm{~nm}$.

\subsubsection{Determine total Polyphenol content}

The total polyphenol content in the extracts was estimated using Folin-Ciocalteu method (Ahmed, Howladar, Mohamed, \& Al-Robai, 2016; McDonald, Prenzler, Antolovich, \& Robards, 2001). $1 \mathrm{ml}$ galic acid solution in ethanol contents: $0.02,0.04,0.06$ and $0.08 \mathrm{mg} / \mathrm{ml}$ added $5 \mathrm{ml}$ Folin-Ciocalteu reagent, then add $4 \mathrm{ml}$ sodium carbonate $(75 \mathrm{~g} / \mathrm{l})$ was added $4.9 \mathrm{ml}$ of distilled water. The mixture was then incubated at room temperature for 90 minutes. Absorbance was taken at $765 \mathrm{~nm}$ and total polyphenol content was expressed as $\mathrm{mg}$ galic acid equivalents per gram of dry samples (mg GEA/g).

\subsubsection{Determine total Flavonoid content}

Determination flavonoid content was by conducted using the method presented by Jia, Tang, and Wu (1999). The Flavonoid in the samples will be yellow complex formulation with $\mathrm{AlCl}_{3}$ solution. The color intensity is directly proportional to the amount of flavonoid content, which is determined at $510 \mathrm{~nm}$ wavelength.

Take $0.5 \mathrm{ml}$ of quercetin solution in methanol with $0.025,0.050,0.075,0.10$ and $0.15 \mathrm{mg} / \mathrm{ml}$ for $2.5 \mathrm{ml}$ of distilled water, adding $0.15 \mathrm{ml} \mathrm{NaNO} 25 \%$, Hold for 5 minutes, then add $0.3 \mathrm{~mL}$ of $\mathrm{AlCl}_{3} 10 \%$, hold for 5 minutes, continue to add $1 \mathrm{ml} \mathrm{NaOH} 1 \mathrm{M}$ and $0.55 \mathrm{ml}$ of distilled water. The absorbance of the solution was determined at $510 \mathrm{~nm}$ wavelength, establishing the calibration curve and the regression equation between the quercetin concentration and the absorbance.

\subsubsection{Determine Total Saponin Content}

The determination total saponin content was based on the method of Nguyen et al. (1995). After being extracted 3 times with ethanol, the samples are dried by a rotary evaporator at $55^{\circ} \mathrm{C}$. Then extraction is dissolved with water and extracted by chloroform to remove lipids and is final extracted by n-butanol. This n-butanol extract was evaporated on a rotary evaporator until constant mass. The n-butanol mass is the mass of total saponin.

Determine to identify compounds of saponin by thin layer chromatography (TLC) with dynamic solvent butanol: ethanol: ammoniac (6:3:3) and observe sample at $365 \mathrm{~nm}$ wavelength.

The figures are evaluated the average, STDEV and graphed by Excel.

\section{Results and Discussion}

\subsection{Total Alkaloid Content}

Table 1. shows that total alkaloid content of Pogang gan's rhizome and small root is higher than white turmeric, excepts tubers and rhizome of 6-month-planted. Total alkaloid content between natural Pogang gan (collected from Kon Bong 2 village, Dak Rong commune, Kbang district, Gia Lai province) and 11-month-cultivated Pogang gan are not significantly different. The highest content of total alkaloid is found in the small roots $(0.273$ $\mathrm{mg} / \mathrm{g}$ ) but root only contribute $5 \%$ productivity. A.R. Srividya et al. found out alkaloid in C. zedoaria planted in India (Srividya, Dhanabal, Ajit Kumar, Sathish Kumar, \& Vishnuvarthan, 2012). Moreover, Abdelazim Ali Ahmed et al. not only found out alkaloid in Achyranthes aspera in Albaha area (Saudi Arabia) (Ahmed, Howladar, Mohamed, \& Al-Robai, 2016), but also specified that the alkaloid content with very high level, about $9.2 \mathrm{mg} / \mathrm{g}$. 
Table 1. Total alkaloid content

\begin{tabular}{ll}
\hline Kind of sample & total alkaloid $(\mathrm{mg} / \mathrm{g})$ \\
\hline Ta0 & $0.197 \pm 0.008$ \\
$\mathrm{TaN}$ & $0.251 \pm 0.006$ \\
$\mathrm{Ta} 1$ & $0.225 \pm 0.005$ \\
$\mathrm{Ta} 2$ & $0.165 \pm 0.005$ \\
$\mathrm{Ta} 3$ & $0.194 \pm 0.005$ \\
$\mathrm{Ta} 4$ & $0.182 \pm 0.004$ \\
$\mathrm{Ta} 5$ & $0.273 \pm 0.004$
\end{tabular}

\subsection{Total Polyphenol Content}

Table 2. Total polyphenol content

\begin{tabular}{|l|l|}
\hline Kind of sample & Total polyphenol $(\mathrm{mg}$ GAE $/ \mathrm{g})$ \\
\hline $\mathrm{Ta} 0$ & $1.81 \pm 0.026$ \\
\hline $\mathrm{TaN}$ & $2.35 \pm 0.054$ \\
\hline $\mathrm{Ta} 1$ & $1.71 \pm 0.043$ \\
\hline $\mathrm{Ta} 2$ & $1.40 \pm 0.064$ \\
\hline $\mathrm{Ta} 3$ & $0.55 \pm 0.052$ \\
\hline $\mathrm{Ta} 4$ & $0.43 \pm 0.064$ \\
\hline $\mathrm{Ta} 5$ & $1.15 \pm 0.068$ \\
\hline
\end{tabular}

Note: GAE: gallic acid equivelent

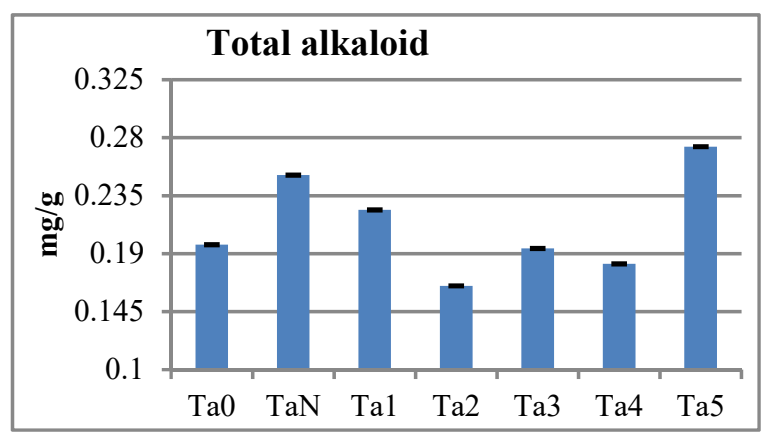

Figure 2. total alkaloid (mg/g)

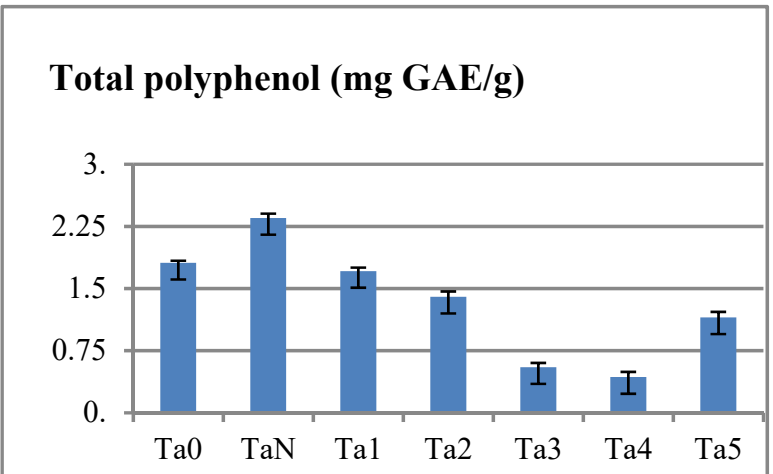

Figure 3. total polyphenol (mg GAE/g)

Table 2. shows that total polyphenol content in rhizomes and tubers of natural Pogang gan is the highest $(2.35 \mathrm{mg}$ $\mathrm{GAE} / \mathrm{g})$, higher than white turmeric $(1.81 \mathrm{mg} \mathrm{GAE} / \mathrm{g})$. Total polyphenol content in rhizomes of 11-month-cultivated Pogang gan is approximated to white turmeric (1.71/1.81mg GAE/g). Polyphenol content accumulated from time to time is shown clearly. This accumulation in the 6-month-cultivated Pogang gan is equal to $81 \%$ of 11 -month-cultivated Pogang gan, and is equal to $59 \%$ of natural pogang gan. The polyphenol content is low in the roots and the lowest in tubers (approximated $0.5 \mathrm{mg} \mathrm{GAE} / \mathrm{g}$ ). The total polyphenol content of the mentioned samples is significantly lower than the polyphenol content of white turmeric in India (34.45 mg GAE/g) (Srividya, Dhanabal, Ajit Kumar, Sathish Kumar, \& Vishnuvarthan, 2012).

\subsection{Total Flavonoid Content}

Table 3. Total flavonoid content

\begin{tabular}{|l|l|}
\hline Kind of sample & Total Flavonoid (mg $Q E / g)$ \\
\hline $\mathrm{Ta} 0$ & $6.06 \pm 0.07$ \\
\hline $\mathrm{TaN}$ & $14.48 \pm 0.10$ \\
\hline $\mathrm{Ta} 1$ & $13.90 \pm 0.05$ \\
\hline $\mathrm{Ta} 2$ & $8.23 \pm 0.02$ \\
\hline $\mathrm{Ta} 3$ & $0.62 \pm 0.02$ \\
\hline $\mathrm{Ta} 4$ & $0.28 \pm 0.01$ \\
\hline $\mathrm{Ta} 5$ & $9.11 \pm 0.01$ \\
\hline
\end{tabular}

Note: QE: quercetin equivelent

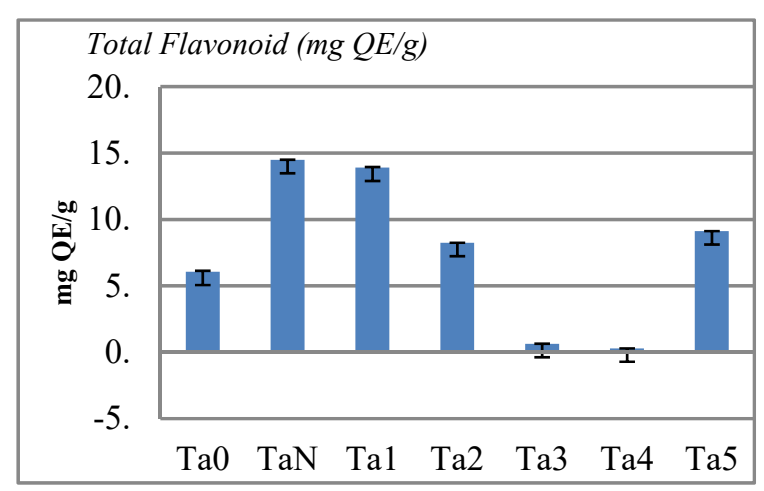

Figure 4. total flavonoid (mg QE/g) 
The member of polyphenol group but flavonoid is the most inportant and the most used. Table 3, shows that flavonoid presents in all the pogang gan samples. The flavonoid content of pogang gan's rhizome is higher than flavonoid of rhizomes and tuber of white turmeric, but flavonoid content of tuber is low. After 11 months cultivated, the flavonoid content in rhizomes is approximated to that content in natural Pogang gan (13.49/14.45 $\mathrm{mg} \mathrm{QE} / \mathrm{g})$ and is doubled higher in white turmeric $(6.06 \mathrm{mg} \mathrm{QE} / \mathrm{g})$. The flavonoid content of pogang gan and white turmeric planted in Vietnam is lower than the flavonoid content of white turmeric cultivated in India (45.56 mg QE/g) (Srividya, Dhanabal, Ajit Kumar, Sathish Kumar, \& Vishnuvarthan, 2012).

\subsection{Total Saponin Content}

Table 4. Total saponin content

\begin{tabular}{|l|l|}
\hline Kind of sample & Total saponin content (\%) \\
\hline SNL & $19.49 \pm 0.062$ \\
\hline $\mathrm{TaN}$ & $7.75 \pm 0.078$ \\
\hline $\mathrm{Ta} 1$ & $4.32 \pm 0.032$ \\
\hline $\mathrm{Ta} 2$ & $0.75 \pm 0.084$ \\
\hline $\mathrm{Ta} 3$ & $5.26 \pm 0.027$ \\
\hline $\mathrm{Ta} 4$ & $2.95 \pm 0.039$ \\
\hline $\mathrm{Ta} 5$ & $4.78 \pm 0.037$ \\
\hline
\end{tabular}

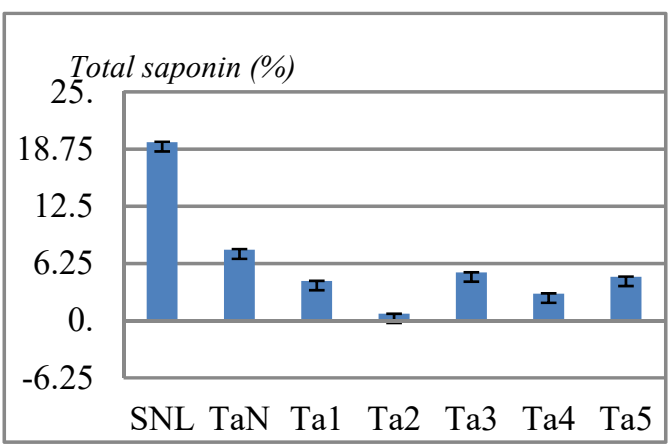

Figure 5. total saponin content (\%)

The saponin in ginseng is ginsenosides, is good for nervous system, hormon, immune system, metabolism and accommodates body activities (Drug Enforcement Administration (DEA), 2010). All parts of pogang gan contain saponin. However, the highest content is in the rhizomes and tubers of 11-month natural pogang gan $(7.75 \%)$, equal to $39.5 \%$ of 6 year old vietnamese ginseng (19.49\%). The saponin content of cultivation highest is in tuber of 11 months $(5.26 \%)$. The saponin content of the natural pogang gan is higher than the cultivated it. The saponin content of tuber is higher than rhizome, but quantity of tuber contribute about $20 \%$ harvest. The saponin content of rhizomes and tubers of 11-month-cultivated pogang gan is between $55.5 \%$ and $67.8 \%$ compared with natural Pogang gan. The accumulation of saponin over time is very clear, affter 11-months is higher than 6 months.

\subsection{The Compounds in Saponin of Pogang Gan}

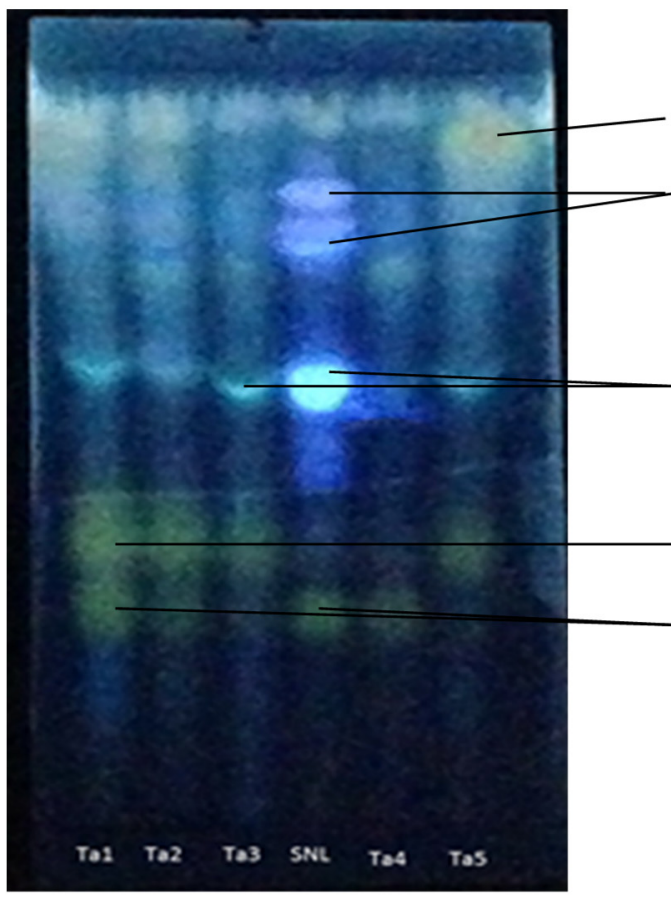

compound is only in pogang gan

compounds are only in $P$. vietnamensis

compound is in two samples but $P$. vietnamensis is more than

compound is only in pogang gan

compound is in two samples

Note: Ta1: rhizomes of cultivated pogang gan after 11 months; Ta2: rhizomes of cultivated pogang gan after 6 months; Ta3: tuber of cultivated pogang gan after 11 months; SNL: rhizome of Panax vietnamensis; Ta4: tuber of cultivated pogang gan after 6 months; Ta5: small roots of cultivated pogang gan after 11 months.

Figure 6 . The compounds in saponin by thin layer chromatography 


\section{Conclusion}

All parts of pogang gan (Curcuma sp.) contain alkaloid, polyphenol, flavonoid. The contents of these compounds are higher than white turmeric. Total saponin content of natural Pogang gan is equal $39.5 \%$ to vietnamese ginseng. And there are some matters which are similar to vietnamese ginseng. After planting 11 months, total alkaloid content is accumulated on rhizomes and tubers. The highest content of alkaloid is found in rhizome. Total polyphenol and flavonoid content are accumulated in rhizomes. Total saponin content is accumulated on rhizome and tuber.

We have found that pogang gan harvested after 11 months has contained more alkaloid, polyphenol and flavonoid than that in white turmeric, wich is favorable to Vietnamese farmer to reduce harvesting time from (normal duration for example several years) to 11 months.

High saponin content, approximately $40 \%$ vietnamensis gingseng. Shows that pogang gan is a valuable tonic.

Affter cultivation pogang gan 11 months productivity 250 gam/tree, among of them rhizome contribute $90 \%$, tuber $5 \%$ and root $5 \%$. The fresh/dry ratio is 7.5 . This is produces a valuable source of medicinal herb.

\section{Acknowledgements}

Thank Chu Yang Shin National garden help us growing pogang gan and thank PhD. Nguyen Quang Vinh for his significant support to analyse the mentioned matters.

\section{References}

Van Tan, P. (2016). Micropropagation of Curcuma Sp., a Threatened Medicinal Plant. Advances in Bioscience and Biotechnology, 7(10), 418-427.

Van Tan, P., \& Vinh, N. Q. (2015). Morphological characteristics and total polyphenol, saponin and alkaloid contents of Curcuma sp. root collected at Kbang dictrict, Gialai province. Science Yearbook of Institute of Ecology and Biological Resources of Vietnam, 2015, 1224-1227.

Drug Enforcement Administration (DEA). (2010). Steroid-drug fact sheet. Retrieved from www.dea.gov

Dutta, B. (2015). Study of secondary metabolite constituents and curcumin contents of six different species of genus Curcuma. Journal of Medicinal Plants, 3(5), 116-119.

Duc, N. M., NHAM, N. T., KASAI, R., ITO, A., YAMASAKI, K., \& TANAKA, O. (1993). Saponins from Vietnamese ginseng, Panax vietnamensis Ha et Grushv. collected in central Vietnam. I. Chemical and pharmaceutical bulletin, 41(11), 2010-2014.

Nguyen, T. T. H., Kinzo, M., Kazuo, Y., Nguyen, M. D., Nguyen, T. N., \& Hiroshi, W. (1995). Crude saponin extracted from Vietnamese gingseng and its major constituent majonoside -R2 attenuate the psychological stress and food-shock stress-induced antinociception in mice. Pharmacology Biochemistry and Behavior, 52(2), 427-432.

Shamsa, F., Monsef, H., Ghamooshi, R., \& Verdian-rizi, M. (2008). Spectrophotometric determination of total alkaloids in some Iranian medicinal plants. Thai J Pharm Sci, 32, 17-20.

Ahmed, A., Howladar, S., Mohamed, H., \& Al-Robai, S. (2016). Phytochemistry, Antimicrobial, Antigiardial and Antiamoebic Activities of Selected Plants from Albaha Area, Saudi Arabia. Br. J. Med. Med. Res, 18(11), 1-8.

McDonald, S., Prenzler, P. D., Antolovich, M., \& Robards, K. (2001). Phenolic content and antioxidant activity of olive extracts. Food chemistry, 73(1), 73-84.

Jia, Z. S., Tang, M. C., \& Wu, J. M. (1999). The determination of flavonoid contents in mulberry and their scavenging effects on superoxide radicals. Food Chemistry, 64, 555-559.

Srividya A. R., Dhanabal S. P., Ajit Kumar, Y., Sathish Kumar, M. N., \& Vishnuvarthan, V. J. (2012). Phytopreventive antithyperlipidemic activity of Curcuma zedoaria. Bulletin of Pharmaceutical Research 2(1), 22-25.

\section{Copyrights}

Copyright for this article is retained by the author(s), with first publication rights granted to the journal.

This is an open-access article distributed under the terms and conditions of the Creative Commons Attribution license (http://creativecommons.org/licenses/by/4.0/). 